\title{
ANALISIS INTENSI KESIAPSIAGAAN SUMBER DAYA MANUSIA RSUD dr. MOHAMMAD SOEWANDHIE SURABAYA DALAM MENGHADAPI BENCANA GEMPA BUMI
}

\author{
Ariyanto Setyoaji *, Christrijogo Sumartomo Waluyo, Setya Haksama \\ Program Studi Magister Manajemen Bencana \\ Sekolah Pasca Sarjana Universitas Airlangga \\ *e-mail : ariyantosked@gmail.com
}

\begin{abstract}
Abstrak
Gempa bumi menjadi bencana dengan banyak kerugian di Indonesia selama 10 tahun terakhir. Untuk mengantisipasi dampak yang lebih lanjut perlu adanya kesiapsiagaan bencana. Kesiapsiagaan merupakan elemen penting dan berperan besar dari kegiatan pengendalian resiko bencana. Parameter pertama faktor kritis kesiapsiagaan untuk mengantisipasi bencana alam adalah pengetahuan dan sikap terhadap resiko bencana. Pengetahuan dan sikap ini akan mempengaruhi intensi individu dalam melakukan upaya penanggulangan kesiapsiagaan terhadap bencana. Penelitian ini bertujuan untuk mengetahui analisis intensi kesiapsiagaan sumber daya manusia RSUD dr. Mohammad Soewandhie Surabaya dalam menghadapi bencan gempa bumi.Data primer dalam penelitian ini didapat melalui penyebaran kuesioner kepada sumber daya manusia RSUD dr. Mohammad Soewandhie Surabaya. Teknik analisis dalam penelitian ini menggunakan uji univariat, bivariat, serta multivariat. Hasil pengujian secara statistik menunjukkan bahwa terdapat pengaruh antara sikap, norma subyektif, dan kontrol perilaku yang dirasa dengan intensi kesiapsiagaan sumber daya manusia RSUD dr. Mohammad Soewandhie Surabaya dalam menghadapi bencana gempa bumi. Hasil selanjutnya menunjukkan bahwa variabel dominan yang mempengaruhi intensi kesiapsiagaan adalah kontrol perilaku yang dirasa. Sikap, norma subyektif, serta kontrol perilaku yang kuat dapat mempengaruhi intensi kesiapisagaan sumber daya manusia RSUD dr. Mohammad Soewandhie Surabaya. Tentunya ini merupakan peluang bagi rumah sakit untuk mengembangkan kesiapsiagaan sumber daya manusia dalam menghadapi bencana menjadi lebih kuat sehingga menumbuhkan perilaku dengan kesiapsiagaan yang kuat dalam menghadapi bencana gempa bumi. intensi kesiapsiagaan yang kuat sangat dibutuhkan agar menumbuhkan sikap dan tindakan seseorang untuk siap dalam menghadapi bencana gempa bumi. Serta menghindari dampak dari bencana yang lebih besar.
\end{abstract}

Kata Kunci : Intensi. Kesiapsiagaan. Gempa Bumi

\section{Analysis of Labor Force Intention Preparedness RSUD dr. Mohammad Soewandhie Surabaya in Dealing with Earthquake Disasters}

\begin{abstract}
The earthquake became a disaster with many losses in Indonesia over the past 10 years. To anticipate further impacts, disaster preparedness is needed. Preparedness is an important element and plays a major role in disaster risk control activities. The first parameter is the critical factor for preparedness to anticipate natural disasters is knowledge
\end{abstract}


and attitudes towards disaster risk. This knowledge and attitude will affect individual intentions in making efforts to overcome disaster preparedness. This study aims to determine the analysis of labor readiness intentions of RSUD dr. Mohammad Soewandhie Surabaya in facing the earthquake disaster.Primary data in this study were obtained through distributing questionnaires to RSUD workforce dr. Mohammad Soewandhie Surabaya. The analysis technique in this study uses univariate, bivariate, and multivariate tests. The test results statistically show that there is an influence between attitudes, subjective norms, and perceived behavioral control with the intentions of the workforce readiness of RSUD dr. Mohammad Soewandhie Surabaya in facing the earthquake disaster. The next result shows that the dominant variable that influences the preparedness intention is perceived behavioral control. Attitudes, subjective norms, and strong behavioral control can affect the intentions of the RSUD workforce preparedness dr. Mohammad Soewandhie Surabaya. Surely this is an opportunity for hospitals to develop workforce preparedness in the face of disasters becoming stronger so as to foster behavior with strong preparedness in the face of earthquake disasters. the intention of strong preparedness is needed to foster one's attitude and actions to be prepared in facing an earthquake disaster. And avoid the impact of a greater disaster.

Keywords: Intention. Preparedness Earthquake

\section{PENDAHULUAN}

Bencana adalah suatu gangguan

serius terhadap sosial, ekonomi dan

lainnya dari suatu masyarakat sehingga

menyebabkan kerugian yang meluas pada

kehidupan manusia maupun dari segi

materi, ekonomi, atau lingkungan dan

melampaui batas kemampuan masyarakat

yang bersangkutan untuk mengatasi

dengan menggunakan sumber daya mereka

sendiri (United Nations International

Strategy for Disaster Reduction - UN

ISDR, 2004).

Negara Kesatuan Republik Indonesia

merupakan salah satu negara yang memiliki julukan Market of Disaster

dikarenakan seringnya mengalami bencana, .

Negara Indonesia berada pada "Ring

of fire" yang merupakan pertemuan antara

3 lempeng raksasa Eurasia, Indo-Australia

dan pasifik. Hal ini lah yang mengakibatkan seringnya terjadi gempa bumi di Indonesia. (Pribadi, 2008). Gempa bumi merupakan salah satu bencana alam terbesar dan sering terjadi didunia disamping letusan gunung berapi dan banjir. Dalam mekanisme penanggulangan bencana, kesiapsiagaan sumber daya manusia merupakan salah satu upaya 
peningkatan produktivitas sumber daya sikap terhadap resiko bencana. manusia yang dilakukan sebelum Pengetahuan dan sikap ini akan terjadinya bencana. Hal ini berhubungan mempengaruhi intensi individu dalam dengan keterampilan dan kemampuan diri. melakukan upaya penanggulangan kesiapsiagaan terhadap bencana. Tujuan

Untuk mengantisipasi dampak yang dari penelitian ini adalah Untuk lebih lanjut perlu adanya kesiapsiagaan mengetahui intensi kesiapsiagaan sumber bencana. Menurut LIPI-UNESCO/ISDR daya manusia RSUD dr. Mohammad (2006), kesiapsiagaan merupakan elemen penting dan berperan besar dari kegiatan pengendalian resiko bencana. Hal ini dapat mengurangi resiko dan mengurangi kerusakan yang diakibatkan bencana. Salah satu bentuk kesiapsiagaan bencana paling penting adalah kesiapsiagaan sumber daya manusia. kesiapsiagaan dilakukan untuk memastikan bahwa sumber daya manusia akan selalu mempunyai kemampuan dalam melakukan upaya penanggulangan bencana secara cepat dan tepat.

\section{Menurut LIPI-UNESCO}

parameter pertama faktor kritis kesiapsiagaan untuk mengantisipasi bencana alam adalah pengetahuan dan
Soewandhie Surabaya dalam menghadapi bencana gempa bumi.

\section{BAHAN DAN METODE}

Penelitian ini menggunakan metode survey analitik non eksperimen. tujuannya mencari hubungan antara varibel independen yaitu sikap, norma subyektif, dan kontrol perilaku sumber daya manusia rumah sakit terhadap variabel dependen yaitu intensi kesiapsiagaan dalam menghadapi bencana gempa bumi di RSUD dr. Mohammad Soewandhie Surabaya. Populasi dalam penelitian ini adalah sumber daya manusia kesehatan di RSUD dr. Mohammad Soewandhie Surabaya. Penelitian ini akan dilaksanakan pada bulan Agustus 2019. 
Jurnal Biosains Pascasarjana Vol. 21 (2019) pp

(C) (2019) Sekolah Pascasarjana Universitas Airlangga, Indonesia

Lokasi penelitian ini akan dilaksanakan di

Didapatkan besar sampel penelitian

RSUD dr. Mohammad Soewandhie adalah 601 responden yang terdiri dari 33

Surabaya. tenaga medis, 456 tenaga paramedis, serta

HASIL 112 tenaga non medis dan paramedis.

Tabel 1. Karateristik responden

\begin{tabular}{|c|c|c|c|}
\hline \multirow[t]{2}{*}{ Karakteristik } & Klasifikasi & $\begin{array}{l}\text { Jumla } \\
\text { h (n) }\end{array}$ & $\begin{array}{l}\text { Persentase } \\
(\%)\end{array}$ \\
\hline & Medis & 33 & $5,5 \%$ \\
\hline \multirow{3}{*}{ Jenis Ketenagaan } & Paramedis & 456 & $75,9 \%$ \\
\hline & $\begin{array}{l}\text { Non Medis dan } \\
\text { Paramedis }\end{array}$ & 112 & $18,6 \%$ \\
\hline & Total & 601 & $100 \%$ \\
\hline
\end{tabular}

Berdasarkan $\quad \overline{\text { tabel }} 1$ diatas $\quad(75,9 \%)$, non medis dan paramedis dengan didapatkan bahwa dari 601 responden jumlah 112 respondeng $(18,6 \%)$, jumlah responden paramedis paling sedangkan paling kecil yaitu medis dengan banyak dengan jumlah 456 responden jumlah 33 responden $(5,5 \%)$.

Tabel 2 Karakteristik Sumber Informasi Responden

\begin{tabular}{|c|c|c|c|}
\hline Karakteristik & Klasifikasi & Jumlah (n) & Presentase $(\%)$ \\
\hline \multirow{2}{*}{ Sumber } & Tidak terpapar informasi & 48 & $8 \%$ \\
\hline & BPBD atau Iklan & 38 & $6,3 \%$ \\
\hline \multirow{2}{*}{ Informasi } & $\begin{array}{l}\text { Video dari RSUD dr. } \\
\text { Mohammad Soewandhie }\end{array}$ & 515 & $85,7 \%$ \\
\hline & Total & 601 & $100 \%$ \\
\hline
\end{tabular}

Berdasarkan Tabel 2 didapatkan bahwa dari 601 responden paling banyak mendapatkan informasi mengenai kebencanaan melalui video dari RSUD dr.
Mohammad Soewandhi dengan jumlah 515 responden $(85,7 \%)$, sedangkan paling sedikit mendapatkan informasi mengenai kebencanaan melalui BPBD atau iklan 
Jurnal Biosains Pascasarjana Vol. 21 (2019) pp

(C) (2019) Sekolah Pascasarjana Universitas Airlangga, Indonesia

dengan jumlah 38 responden $(6,3 \%)$ tidak pernah terpapar informasi mengenai

Namun masih ada 48 responden (8\%) yang kebencanaan.

Tabel 3. Karakteristik Pelatihan Kebencanaan Responden

\begin{tabular}{cccc}
\hline Karakteristik & \multicolumn{1}{c}{ Klasifikasi } & Jumlah (n) & Presentase (\%) \\
& $\begin{array}{c}\text { Tidak ada } \\
\text { pelatihan kebencaan }\end{array}$ & 299 & $49,8 \%$ \\
\cline { 2 - 4 } $\begin{array}{c}\text { PPGD atau } \\
\text { Pelatihan } \\
\text { kebencanaan }\end{array}$ & BTCL & 219 & $36,4 \%$ \\
\cline { 2 - 3 } & $\begin{array}{c}\text { Manajemen } \\
\text { Bencana }\end{array}$ & 12 & $2 \%$ \\
\cline { 2 - 3 } & K3RS & 63 & $10,5 \%$ \\
\hline & 601 & $100 \%$ \\
\hline
\end{tabular}

Berdasarkan tabel 3 didapatkan bahwa sebanyak 299 responden $(49,8 \%)$ tidak pernah mendapatkan pelatihan kebencanaan dan paling sedikit mendapatkan pelatihan K3RS sebanyak 8

\section{Hasil Analisis Uji Univariat}

Hasil analisis

univariat

merupakan distribusi frekuensi untuk mendapatkan gambaran dari variabel dependen maupun variabel independen. Adapun berikut hasil analisis univariat yang terdiri dari gambaran intensi sumber responden $\quad(1,3 \quad \%)$. daya manusia rumah sakit dalam kesiapsiagaan bencana gempa bumi, gambaran sikap, gambaran norma subyektif, dan gambaran persepsi kontrol perilaku. 
Tabel 4. Distribusi Frekuensi Intensi Kesiapsiagaan Bencana Gempa Bumi

\begin{tabular}{llcc} 
Variabel & Kategori & Frekuensi (n) & $\begin{array}{c}\text { Presentase } \\
(\mathbf{\%})\end{array}$ \\
\hline \multirow{2}{*}{ Intensi } & Kuat & 316 & $52,6 \%$ \\
\cline { 2 - 4 } & Lemah & 285 & $47,4 \%$ \\
\hline \multirow{2}{*}{ Sikap } & Positif & 308 & $51,2 \%$ \\
\cline { 2 - 4 } & Negatif & 293 & $48,8 \%$ \\
\hline $\begin{array}{l}\text { Norma } \\
\text { Subyektif }\end{array}$ & Kuat & 318 & $52,9 \%$ \\
\cline { 2 - 4 } $\begin{array}{l}\text { Persepsi } \\
\text { Kontrol } \\
\text { Perilaku }\end{array}$ & Kuat & 283 & $47,1 \%$ \\
\cline { 2 - 4 } & Lemah & 300 & $49,9 \%$ \\
\hline $\begin{array}{l}\text { asarkan hasil pada tabel 5.12 } \\
\text { and }\end{array}$ & & norma subyektif yang kuat sebanyak 318
\end{tabular}

didapatkan bahwa dari 601 responden responden $(52,9 \%)$, namun memiliki yang memiliki intensi kuat sebanyak 316 persepsi kontrol perilaku yang dirasa responden $(52,6 \%)$, memiliki sikap yang lemah sebanyak 301 responden $(50,1 \%)$. kuat sebanyak 308 responden $(51,2 \%)$,

\section{Hasil Analisis Uji Bivariat}

Uji yang digunakan dalam penelitian ini adalah Uji Chi Square Adapun hasil yang didapat dapat dilihat dalam tabel sebagai berikut :

Tabel 5 Hasil Uji Chi Square hubungan sikap dengan intensi kesiapsiagaan bencana gempa bumi di RSUD dr. Mohammad Soewandhie Surabaya

\begin{tabular}{lcccccccc}
\hline \multirow{2}{*}{ Sikap } & \multicolumn{4}{c}{ Intensi } & \multicolumn{2}{c}{ Total } & \multirow{2}{*}{ OR 95\% CI } & \multirow{2}{*}{ p-value } \\
\cline { 2 - 7 } & \multicolumn{2}{c}{ Kuat } & \multicolumn{2}{c}{ Lemah } & \multicolumn{2}{c}{$\%$} & \\
\cline { 2 - 8 } & $\mathrm{n}$ & $\%$ & $\mathrm{n}$ & $\%$ & $\mathrm{n}$ & $\%$ & & \multirow{2}{*}{0,00} \\
\hline Positif & 256 & 83,1 & 52 & 16,9 & 308 & 100 & 19 & \\
\hline Negatif & 60 & 20,5 & 233 & 79,5 & 293 & 100 & $12,7-28,9$ & \\
\hline Jumlah & 316 & 52,6 & 285 & 47,4 & 601 & 100 & & \\
\hline
\end{tabular}

Berdasarkan tabel 5 diatas responden yang memiliki sikap positif diketahui bahwa sebanyak 83,1\% dengan intensi kesiapsiagaan terhadap 
bencana kuat sedangkan sebanyak $79,5 \%$ responden yang memiliki sikap negatif dengan intensi kesiapsiagaan terhadap bencana juga lemah.

Sumber daya manusia yang memiliki sikap positif ini cenderung mengungkapkan bahwa kesiapsiagaan merupakan hal yang penting. Berdasarkan analisis selanjutnya didapatkan juga bahwa sikap memiliki pengaruh yang signifikan terhadap intensi kesiapsiagaan sumber daya manusia RSUD dr. Mohammad Soewandhie Surabaya dengan nilai $p$-value sebesar 0,00 (lebih kecil dari nilai alpha $=$ $0,05)$ yang berarti terdapat pengaruh antara sikap sumber daya manusia rumah sakit dengan intensi kesiapsiagaan bencana gempa bumi di RSUD dr. Mohammad Soewandhie Surabaya. Kemudian didapatkan pula bahwa sumber daya manusia dengan sikap yang postif berpeluang sebesar 19 kali untuk memiliki intensi kuat dibandingkan dengan sumber daya manusia dengan sikap negatif.. Salah satu hal yang melatar belakangi sikap adalah pengetahuan dasar terhadap kesiapsiagaan bencana. Hal ini sejalan dengan hasil yang didapatkan bahwa sebanyak $98,7 \%$ responden memiliki tingkat pengetahuan yang baik mengenai kebencanaan.

Tabel 6 Hasil Uji Chi Square hubungan Norma Subyektif dengan intensi kesiapsiagaan bencana gempa bumi di RSUD dr. Mohammad Soewandhie Surabaya

\begin{tabular}{|c|c|c|c|c|c|c|c|c|}
\hline \multirow{3}{*}{$\begin{array}{c}\text { Norma } \\
\text { Subyektif }\end{array}$} & \multicolumn{4}{|c|}{ Intensi } & \multirow{2}{*}{\multicolumn{2}{|c|}{ Total }} & \multirow{3}{*}{ OR $95 \% \mathrm{CI}$} & \multirow{3}{*}{$\mathrm{p}$-value } \\
\hline & \multicolumn{2}{|c|}{ Kuat } & \multicolumn{2}{|c|}{ Lemah } & & & & \\
\hline & $\mathrm{n}$ & $\%$ & $\mathrm{n}$ & $\%$ & $\mathrm{n}$ & $\%$ & & \\
\hline Kuat & 222 & 69,8 & 96 & 30,2 & 318 & 100 & 5 & \\
\hline Lemah & 94 & 33,2 & 189 & 66,8 & 283 & 100 & $3,3-6,7$ & 0,00 \\
\hline Jumlah & 316 & 52,6 & 285 & 47,4 & 601 & 100 & & \\
\hline
\end{tabular}

diketahui bahwa sebanyak $69,8 \%$ responden yang memiliki norma subyektif responden yang memiliki norma subyektif lemah dengan intensi kesiapsiagaan kuat dengan intensi kesiapsiagaan terhadap terhadap bencana juga lemah. Hasil 
statistik diperoleh nilai p-value sebesar 0,00 (lebih kecil dari nilai alpha $=0,05$ ) yang berarti ada hubungan bermakna antara norma subyektif yang dimiliki sumber daya manusia rumah sakit dengan intensi kesiapsiagaan bencana gempa bumi di RSUD dr. Mohammad Soewandhi Surabaya. Norma subyektif disini artinya pengaruh orang-orang terdekat baik dari lingkungan kerja maupun atasan. Pada umumnya, individu yang yakin bahwa kebanyakan orang terdekat akan menyetujui dirinya menampilkan perilaku tertentu. Adanya motivasi untuk mengikuti perilaku tertentu menimbulkan tekanan sosial untuk melakukannya. (ajzen, 2005).

Hasil focus group discussion (FGD) yang dilakukan diperoleh bahwa selama ini sosialisasi bahkan pelatihan kesiapsiagaan menghadapi bencana belum sepenuhnya diikuti oleh sumber daya manusia. Hal ini dibuktikan oleh hasil penelitian bahwa sebanyak $49,8 \%$ responden belum mendapatkan pelatihan kebencanaan. Tentunya ini merupakan peluang bagi rumah sakit untuk mengembangkan kesiapsiagaan sumber daya manusia dalam menghadapi bencana menjadi lebih kuat sehingga menumbuhkan perilaku dengan kesiapsiagaan yang kuat dalam menghadapi bencana gempa bumi. intensi kesiapsiagaan yang kuat sangat dibutuhkan agar menumbuhkan sikap dan tindakan seseorang untuk siap dalam menghadapi bencana gempa bumi. Serta menghindari dampak dari bencana yang lebih besar.

Tabel 7 Hasil Uji Chi Square hubungan Kontrol Perilaku dirasa dengan intensi kesiapsiagaan bencana gempa bumi di RSUD dr. Mohammad Soewandhie Surabaya

\begin{tabular}{|c|c|c|c|c|c|c|c|c|}
\hline \multirow{3}{*}{$\begin{array}{c}\text { Kontrol } \\
\text { perilaku } \\
\text { dirasa }\end{array}$} & \multicolumn{4}{|c|}{ Intensi } & \multirow{2}{*}{\multicolumn{2}{|c|}{ Total }} & \multirow{3}{*}{ OR $95 \% \mathrm{CI}$} & \multirow{3}{*}{$\mathrm{p}$-value } \\
\hline & \multicolumn{2}{|c|}{ Kuat } & \multicolumn{2}{|c|}{ Lemah } & & & & \\
\hline & $\mathrm{n}$ & $\%$ & $\mathrm{n}$ & $\%$ & $\mathrm{n}$ & $\%$ & & \\
\hline Kuat & 255 & 85 & 45 & 15 & 300 & 100 & 22,3 & م 00 \\
\hline Lemah & 61 & 20,3 & 240 & 79,7 & 301 & 100 & $14,6-34,1$ & 0,00 \\
\hline Jumlah & 316 & 52,6 & 285 & 47,4 & 601 & 100 & & \\
\hline
\end{tabular}


Jurnal Biosains Pascasarjana Vol. 21 (2019) pp

(C) (2019) Sekolah Pascasarjana Universitas Airlangga, Indonesia

Berdasarkan Tabel 7 diatas bencana kuat sedangkan sebanyak $79,7 \%$

diketahui bahwa sebanyak $85 \%$ responden yang memiliki kontrol perilaku kuat dengan intensi kesiapsiagaan terhadap dengan intensi kesiapsiagaan terhadap bencana juga lemah. Hasil statistik diperoleh nilai $\mathrm{p}$-value sebesar 0,00 (lebih kecil dari nilai alpha $=0,05)$ yang berarti ada hubungan bermakna antara kontrol perilaku sumber daya manusia rumah sakit dengan intensi kesiapsiagaan bencana gempa bumi di RSUD dr. Mohammad Soewandhi Surabaya. Faktor penghambat dapat diperoleh dari faktor lingkungan contohnya pelatihan kesiapsiagaan dalam menghadapi kebencanaan masih belum diperoleh oleh semua sumber daya manusia RSUD dr. Mohammad Soewandhie Surabaya. Faktor penghambat yang lain adalah belum adanya Standard Operating Procedure atau kebijakan dalam kesiapsiagaan menghadapi bencana gempa bumi yang jelas mengenai hak dan responden yang memiliki kontrol perilaku lemah

kewajiban para petugas kesehatan sehingga terjadi keraguan para petugas kesehatan RSUD dr. Soewandhie Surabaya apabila petugas kesehatan melakukan bantuan atau ikut serta tim penanggulangan bencana gempa bumi, seperti masalah kesejahteraan, waktu libur, bagaimana manajemen waktu overtime ketika terjadi bencana.

Dalam menghadapi

kesiapsiagaan bencana terutama bencana gempa bumi diperlukan juga kerjasama dan peran serta seluruh karyawan RSUD dr. Soewandhie, bukan hanya peran tenaga medis dan paramedis, karena ketangguhan dari rumah sakit tahan bencana harus dilakukan dengan kerjasama oelh semua karyawan RSUD dr. Soewandhie yang siaga dan tangguh bencana.

\section{Hasil Analisi Uji Multivariat}


Jurnal Biosains Pascasarjana Vol. 21 (2019) pp

(C) (2019) Sekolah Pascasarjana Universitas Airlangga, Indonesia

Analisis multivariat dalam sumber daya manusia rumah sakit dalam penelitian ini menggunakan Uji Regresi menghadapi bencana gempa bumi di Logistik yang bertujuan untuk mengetahui RSUD dr. Mohammad Soewandhie variabel independen yang dominan Surabaya. Adapun hasil yang didapat mempengaruhi intensi kesiapsiagaan adalah sebagai berikut :

Tabel 8. Hasil Uji Regresi Logistik Variabel dominan yang mempengaruhi intensi kesiapsiagaan bencana gempa bumi di RSUD dr. Mohammad Soewandhie Surabaya

\begin{tabular}{|l|c|c|c|c|c|}
\hline \multirow{2}{*}{ Variabel } & \multirow{2}{*}{ B } & \multirow{2}{*}{$\boldsymbol{P}$-value } & \multirow{2}{*}{ OR } & \multicolumn{2}{c|}{ 95\% CI } \\
\cline { 5 - 6 } & & & & Lower & Upper \\
\hline Sikap & 1,8 & 0,000 & 5,76 & 3,49 & 9,49 \\
\hline Norma Subyektif & 0,3 & 0,218 & 1,35 & 0,84 & 2,18 \\
\hline Kontrol Perilaku dirasa & 2 & 0,000 & 7,68 & 4,64 & 12,69 \\
\hline
\end{tabular}

Berdasarkan tabel 8 didapatkan bencana gempa bumi di RSUD dr.

bahwa hasil OR (Odd Ratio) dari ketiga variabel independen diatas yang paling banyak terdapat pada variabel kontrol perilaku dirasa yaitu sebesar 7,68 yang berarti variabel paling dominan mempengaruhi intensi kesiapsiagaan

\section{KESIMPULAN}

Hasil analisis univariat didapatkan bahwa sebagian besar sumber daya manusia di RSUD dr. Mohammad Soewandhie Surabaya menunjukkan sikap yang positif terhadap kesiapsiagaan menghadapi bencana gempa bumi
Mohammad Soewandhie Surabaya adalah kontrol perilaku yang dimiliki sumber daya manusia rumah sakit. Adapun variabel yang memiliki $P$-value lebih dari 0,05 yaitu norma subyektif sebesar 0,218 merupakan variabel confounding.

Sebagian besar Sumber Daya Kesehatan RSUD dr. Mohammad Soewandhie Surabaya mempunyai norma subyektif dan Instensi yang kuat dalam menghadapi bencana gempa bumi. 
Kontrol perilaku dirasa atau

perceived behavioral control

(PBC) yang lemah dari Sumber

Daya Kesehatan RSUD dr.

Mohammad Soewandhie Surabaya

dalam menghadapi bencana gempa

bumi.

1. Kontrol perilaku dirasa atau

perceived behavioral control (PBC)

berpengaruh terhadap intensi

kesiapsiagaan sumber daya kesehatan

RSUD dr. Mohammad Soewandhie

Surabaya dalam menghadapi bencana

gempa bumi .

\section{DAFTAR PUSTAKA}

Abdalla, S. M. 2012. Medical and Para Medical Staff Awareness About Disaster Management at Assiut University Hospital. Journal AAMJ Vol. 10, No 3, September $2012: 67-93$.

Alshehri, B. (2016). Emergency nurses' preparedness for disaster in the Kingdom of Saudi Arabia. Journal of Nursing Education and Practice, 7(3) : 101-114.

Diab, M. G. and Mabrouk, S.M. 2015 The Effect of Guidance Booklet on Knowledge and Attitudes of Nurses Regarding Disaster Preparedness at Hospital. Journal of Nursing Education and Practice, 2015 Vol 5. No $9: 17-31$.
Husna, C. 2012. Faktor - factor yang mempengaruhi Kesiapsiagaan Bencana di RSUDZA Banda Aceh. Idea Nursing Journal Vol III. No2. $2012: 10$ - 19.

Kementerian Kesehatan Republik Indonesia. 2007. Lesson Learnt Penanganan Krisi Kesehatan Akibat Gempa Bumi Di Provinsi Daerah Istimewa Yogyakarta dan Jawa Tengah 27 Mei 2006. Jakarta: Kementerian Kesehatan Republik Indonesia.

Kementerian Kesehatan Republik Indonesia. 2007. Pedoman Teknis Penanggulangan Krisis Kesehatan Akibat Bencana. Jakarta: Kementerian Kesehatan Republik Indonesia.

Komisi Akreditasi Rumah Sakit. 2018. Standar Nasional Akreditasi Rumah Sakit Edisi 1.

Lembaga Penanggulangan Bencana Pimpinan Pusat Muhammadiyah. 2016. Standar Rumah Sakit Aman Bencana. Muhammadiyah Disaster Management Center

Maeda, T. Kotera, S. Matsuda, N. dan Edwards , G.D. . 2018. Disaster Readiness among Nurses in Japan : Current Status Following the Great East Japan Earthquake. International Journal of Nursing June 2016. Vol 3 No 1: 15 - 28.

Mulyadi, I.M. Syahrul, I. Mudatsir. Jasa, Z. 2016. Evaluasi \{artisipasi Pendidikan Kebencanaan pada MAhasiswa Fakultas Kedokteran Universitas Syiah Kuala ( Setelah Mengikuti Blok Disaster Management). Jurnal Kedokteran Syiah Kuala. Volume 16 Nomer 3 : 146 - 150.

Munandar, A. dan Wardaningsih,S. 2018. Kesiapsiagaan Perawat dalam Penatalaksannan Aspek Psikologis Akibat Bencana

Alam 
Ogedegbe, C. Nyrenda, T. Delmoro, G. Yamin, E. Feldman, J. 2012. Health Care Workers and Disaster Preparedness : Barriers and Facilitators of Wilingness to Respond.https://www.ncbi.nlm.nih.gov/pm c/articles/PMC34077728

Pan American Organization, Worh Health Organization. Safe Hospital Checklist.

Pourvakhshoori, S. N. Khankeh, H. R. dan Mohammadi, F. 2015. Emergency and Disaster Preparedness in Nurses : A Concept Analysis. Journal of Holistic Nursing and Midwifery. Spring 2017. 27 (1) : 35-43.

Putra, H. A. 2018. Studi Kualitatif Kesiapsiagaan Tim Komite Bencana Rumah Sakit PKU Muhammadiyah Bantul dalam Menghadapi Bencana. Health Science and Pharmacy Journal Vol. 2, No 1, April 2018: 8 -15.

Rezael, F. Maracy, R. M. Yarmohammadian, M.H. dan Sheikbardsiri, H. 2018. Hospital Preparedness using WHO guideline : A systematic review and metaanalysis.Hongkong journal of Emergency Medicine Vol. 25(4) : $211-222$

Rizqillah, F. A. dan Suna, J. Indonesian Emergency Nurses Preparedness to Respond to Disaster : A Descriptive
Survey. 2018. Australian emergency Care. https

://doi.org/10.1016/j.auec.2018.04.001.

Saanin, Syaiful. 2010. Pedoman Perencanaan Penyiagaan Bencana Rumah Sakit (P3BRS) (Hospital Disaster Plan) Rumah Sakit Umum Pusat Dr. M. Djamil Padang.

Standar Nasional Indonesia. 2013. Layanan Kemanusiaan Dalam Bencana. Badan Standarisasi Nasional.

Supriyono, P. 2014. Seri Pendidikan Pengurangan Risiko Bencana Gempa Bumi.

World Health Organization. 2011. Hospital Emergency Response Checklist: An All-Hazard Tool for Hospital Administrators and Emergency Managers. WHO Regional Office for Europe. Copenhagen.

World Health Organization. 2015.Comprehensive Safe Hospital Network 